\title{
Performance Assessment of Several Filters for Removing Salt and Pepper Noise, Gaussian Noise, Rayleigh Noise and Uniform Noise
}

\author{
Prashant Dwivedy \\ Department of Electrical \& \\ Electronics Engineering, National \\ Institute of Technical Teachers' \\ Training \& Research, Bhopal, India
}

\author{
Anjali Potnis \\ Department of Electrical \& \\ Electronics Engineering, National \\ Institute of Technical, Teachers' \\ Training \& Research, Bhopal, India
}

\author{
Madhuram Mishra \\ Department of Electrical \& \\ Electronics Engineering, National \\ Institute of Technical Teachers' \\ Training \& Research, Bhopal, India
}

\begin{abstract}
Digital images are prone to a variety of noises. Denoising of image is a crucial fragment of image reconstruction procedure. Noise gets familiarized in the course of reception and transmission, acquisition and storage \& recovery processes. Hence de-noising an image becomes a fundamental task for correcting defects produced during these processes. A complete examination of the various noises which corrupt an image is included in this paper. Elimination of noises is done using various filters. To attain noteworthy results various filters have been anticipated to eliminate these noises from Images and finally which filter is most suitable to remove a particular noise is seen using various measurement parameters.
\end{abstract}

Keywords- Image de-noising; Image restoration techniques; Noise models; Average filter; Median filter; Poisson noise; Gaussian noise; PSNR; MS.

\section{INTRODUCTION}

During processing of digital images by means of digital computers de-noising or removal of noise is very essential [1]. Noise is an unwanted signal in image which gives change in visibility of any image and occurs usually due to thermal or electrical signals such as from sensors or environmental conditions. The problem at hand is removing the noise of an image while preserving its main features (edges, textures, colors, contrast, etc.) This has been widely examined over the last two decades and several types of approaches have been developed. There are two domain processes available for restoring the image, first one is spatial domain and second one is frequency domain. In the spatial domain filtering action is done by operating on the pixel of the digital image directly for restoring the image. On the other hand filtering action is completed by in frequency domain by mapping spatial domain into frequency domain of the image function by taking Fourier transform of the image function. After the filtering, in order to conclude the restored image we have to re map the image into spatial domain by taking inverse Fourier transform. Noise may be categorized as multiplicative noise for example speckle noise, substitutive noise for example salt and pepper noise and additive noise for example Gaussian noise. In this paper first image is occupied and noise to be deal is added to image to make it a noisy image and then noisy image is passed by filters. It becomes significant to de-noise the image before smearing to various applications [2].The principle approach of image denoising is filtering. Numerous filters are used to eliminate noise such as averaging filters, median filters, mean filters etc. The image quality is measured by various performance parameters like the peak signal to noise ratio (PSNR) and mean square error (MSE) [3].

\section{NOISE MODELS}

Noise is an outcome of inaccuracy in image acquisition process [4] that results in pixel values that do not imitate true intensities of the actual picture. Using probability density functions we can describe a set of noise models. The most occurring noises in digital images are poisson noise, exponential noise, salt and pepper noise, Gaussian noise, multiplicative noise, Rayleigh noise, Erlang noise or Gamma noise and uniform noise. Following, these noises are discussed at stretch.

\section{A. Salt and Pepper Noise}

An image comprising salt-and-pepper noise will have dark pixels in bright regions and bright pixels in dark regions. It is also sometimes called Impulse Noise. This noise is usually caused by sudden and sharp disturbances in the image signal. It often presents itself as sparsely occurring black and white pixels. This type of noise can be produced by dead pixels, analog-to-digital convertor errors, bit errors in transmission, etc. If $a=0$ (black) and $b=1$ (white) then probability distribution is specified by

$$
P(z)=\left\{\begin{array}{l}
P_{a} \text { for } z=a_{j} \\
P_{b} \text { for } z=b ; \\
0 \text { otherwise }
\end{array}\right.
$$




\section{B. Gaussian Noise}

Gaussian noise is statistical in nature having a probability density function equivalent to that of the normal distribution. Gaussian noise is normally a set of values taken from a zero mean Gaussian distribution [6] which is added to every pixel value. The distribution is given by the expression

$$
P(z)=\frac{1}{\sigma \sqrt{2 \pi}} e^{-\frac{(z-\mu)^{2}}{2 \sigma^{2}}}
$$

Where $\mu=$ mean of random variable of $z, z=$ gray level and $\sigma^{2}=$ variance of $z$

\section{Rayleigh Noise}

The Rayleigh noise follows the Rayleigh distribution

$$
P(z)= \begin{cases}\frac{2}{b}(z-a) e^{-\frac{(x-a)^{2}}{b}} & \text { for } z \geq a ; \\ 0 & \text { for } z<a_{j}\end{cases}
$$

Rayleigh density can be used to approximate skewed image histograms [9].

\section{Uniform Noise}

This sort of noise generates a noise sequence and follows the uniform distribution function [11] with value ranging from $\mathrm{a}$ to $\mathrm{b}$ and is added uniformly to all the pixels of the image. The PDF of uniform noise [12] is specified by

$$
p(z)=\left\{\begin{array}{c}
\frac{1}{b-a} \text { if } a \leq z \leq b \\
0 \quad \text { otherwise }
\end{array}\right.
$$

\section{FilTERING TeChNiQUES}

Removal of noise from the corrupted image is done by filtering. There are two types of filtering techniques [13]. First one being spatial filtering and second one is frequency filtering.

Spatial filtering is the filtering operations that are accomplished straight on the pixels of image. In Spatial Domain the filtering operation [14] is done by convolving the image pixels with the pixels of the mask. A mask is a small sub image, often of size $3 \times 3$ pixels. The mask size is varied according to the requirement. These include the following classes of filters

- Mean filters

- Order statistics filters

- Adaptive filters

\section{A. Arithmetic Mean Filter}

In this type of mean filter the middle pixel value of the mask is replaced with the arithmetic mean [15] of all the pixel values within the filter window. It calculates the average value of the ruined image $g(x, y)$ in the area defined by $S_{x, y}$. The assessment of the reestablished image $f(x, y)$ at any point $(\mathrm{x}, \mathrm{y})$ is

$$
f(x, y)=\frac{1}{m n} \sum_{(s, t) \in S_{x, y}} g(s, t)
$$

\section{B. Geometric Mean Filter}

The working of a geometric mean filter is same as the arithmetic mean filter; the only difference is that as a replacement for taking the arithmetic mean the geometric mean is taken. The reestablished image is given by the expression

$$
f(x, y)=\left[\prod_{(s, t) \in S_{x y}} g(s, t)\right]^{\frac{1}{m n}}
$$

\section{Median Filter}

Order-statistics filters are built on assembling the pixels enclosed in the mask. Median filter comes under this class of filters. Median filter exchanges the value of a pixel with the median value of the gray intensities within the filter window [17] or mask. Median filters are very effective for impulse noise.

$$
f(x, y)=\underset{(s, t) \in S_{x y}}{\operatorname{median}}\{g(s, t)\}
$$

\section{Max and Min filter}

The max filter is beneficial for finding the brightest points in an image. Since pepper noise has very small values, it is condensed by this filter as an outcome of the max selection processing the sub image area $S x, y$.

$$
f(x, y)=\max _{(s, t) \in S_{x y}}\{g(s, t)\}
$$

The min filter is valuable for finding the darkest points in an image. Also, it decreases salt noise [18] as a result of the min operation.

$$
f(x, y)=\min _{(s, t) \in S_{x y}}\{g(s, t)\}
$$

\section{E. Midpoint filter}

This filter computes the midpoint between the maximum and minimum values in the area included by the filter. This filter works finest for arbitrarily distributed noise like Gaussian noise.

$$
f(x, y)=\frac{1}{2}\left[\max _{(s, t) \in S_{x y}}\{g(s, t)\}+\min _{(s, t) \in S_{x y}}\{g(s, t)\}\right]
$$




\section{Performance Measurement Parameters}

Consider an image of dimensions $\mathrm{M}$ and $\mathrm{N}$. If $f(x, y)$ is the original image and $g(x, y)$ is the distorted image then the various measurement parameters are described as follows.

\section{A. Mean Square Error (MSE)}

The MSE [19] is cumulative squared error between the compressed and the original image. It is calculated using

$M S E=\frac{1}{M N} \sum_{0}^{M-1} \sum_{0}^{N-1}\|f(x, y)-g(x, y)\|$

\section{B. Peak Signal to Noise Ratio (PSNR)}

The PSNR is used to determine the ratio among the maximum power of a signal and power of corrupting noise. The formula of PSNR is given as

$$
P S N R=10 \log _{10}\left[\frac{M * N}{M S E}\right]
$$

\section{Average Difference (AD)}

The average difference is specified by the formula

$$
|f(x, y)-g(x, y)|
$$

D. Maximum Difference (MD)

The maximum difference is specified by the formula

$$
\max |f(x, y)-g(x, y)|
$$

\section{E. Normalized Absolute Error (NAE)}

The normalized error is specified by

$$
y=N A E=\frac{\sum_{x=1}^{w} \sum_{y=1}^{W}(f(x, y) * g(x, y))}{\sum_{x=1}^{M} \sum_{y=1}^{N}(f(x, y))^{2}}
$$

\section{F. Structural Content (SC)}

$\mathrm{SC}$ is correlation based measure and measures the similarity between two images. It is specified by the equation

$$
S C=\frac{\sum_{i=1}^{M} \Sigma_{j=1}^{N}(y(i, j))^{2}}{\sum_{i=1}^{M} \Sigma_{j=1}^{N}(x(i, j))^{2}}
$$

\section{Simulation Result and Analysis}

Simulation has been run on Matlab using gray scale image 'lena.bmp' of size 512 x 512 as a test image shown in Fig 1

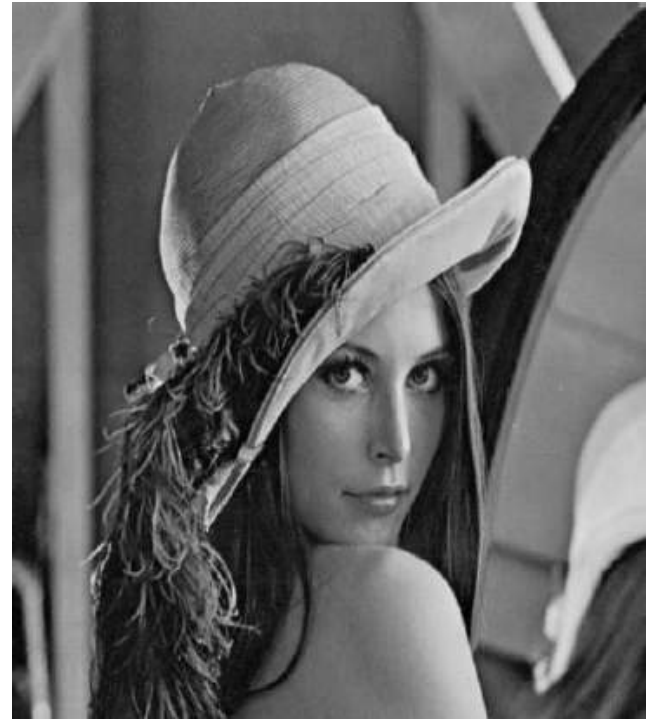

Fig. 1. Test Image Lena

Table 1 shows the different measurement parameters after applying all the filters for Rayleigh noise.

TABLE I. RAYLEIGH NOISE

\begin{tabular}{|l|c|c|c|c|c|c|}
\hline FILTER & MSE & PSNR & AD & MD & NAE & SC \\
\hline $\begin{array}{l}\text { Arithmetic } \\
\text { Filter }\end{array}$ & 4.0900 & 42.0136 & 0.4832 & 100 & 0.0049 & 0.9993 \\
\hline $\begin{array}{l}\text { Geometric } \\
\text { Filter }\end{array}$ & 5.3772 & 40.8252 & 0.6426 & 118 & 0.0065 & 0.9977 \\
\hline $\begin{array}{l}\text { Harmonic } \\
\text { Filter }\end{array}$ & 8.8568 & 38.6581 & 1.0787 & 156 & 0.0109 & 0.9980 \\
\hline $\begin{array}{l}\text { Contra- } \\
\text { Harmonic } \\
\text { Filter }\end{array}$ & 252.150 & 24.1142 & 98.735 & 252 & 0.9969 & 160.65 \\
\hline $\begin{array}{l}\text { Median } \\
\text { Filter }\end{array}$ & 4.4275 & 41.6693 & 0.5988 & 135 & 0.0060 & 0.9970 \\
\hline $\begin{array}{l}\text { Max and } \\
\text { Min Filter }\end{array}$ & 70.7250 & 29.6351 & 9.1765 & 181 & 0.0926 & 1.0147 \\
\hline $\begin{array}{l}\text { Mid-Point } \\
\text { Filter }\end{array}$ & 15.9580 & 36.1010 & 2.1084 & 89 & 0.0213 & 0.9975 \\
\hline
\end{tabular}

Table 2 shows the different measurement parameters after applying all the filters for Salt and Pepper noise.

TABLE II. SALT AND PEPPER NOISE

\begin{tabular}{|l|c|c|c|c|c|c|}
\hline FILTER & MSE & PSNR & AD & MD & NAE & SC \\
\hline $\begin{array}{l}\text { Arithmetic } \\
\text { Filter }\end{array}$ & 27.0425 & 33.8103 & 3.4363 & 113 & 0.0347 & 0.9977 \\
\hline $\begin{array}{l}\text { Geometric } \\
\text { Filter }\end{array}$ & 30.5430 & 33.2817 & 8.5275 & 232 & 0.0861 & 0.9982 \\
\hline $\begin{array}{l}\text { Harmonic } \\
\text { Filter }\end{array}$ & 34.0357 & 32.8115 & 9.1250 & 231 & 0.0921 & 0.9996 \\
\hline Contra- & 252.125 & 24.1146 & 98.708 & 252 & 0.9966 & 153.33 \\
\hline
\end{tabular}




\begin{tabular}{|l|l|l|l|l|l|l|}
\hline $\begin{array}{l}\text { Harmonic } \\
\text { Filter }\end{array}$ & & & & & & \\
\hline $\begin{array}{l}\text { Median } \\
\text { Filter }\end{array}$ & 9.2991 & 38.4464 & 1.3019 & 135 & 0.0131 & 0.9978 \\
\hline $\begin{array}{l}\text { Max and } \\
\text { Min Filter }\end{array}$ & 94.1594 & 28.3922 & 17.950 & 229 & 0.1812 & 1.0191 \\
\hline $\begin{array}{l}\text { Mid-Point } \\
\text { Filter }\end{array}$ & 15.9580 & 36.1010 & 2.1084 & 89 & 0.0213 & 0.9975 \\
\hline
\end{tabular}

Table 3 shows the different measurement parameters after applying all the filters for Gaussian noise.

TABLE III. GAUSSIAN NOISE

\begin{tabular}{|c|c|c|c|c|c|c|}
\hline FILTER & MSE & PSNR & $\mathbf{A D}$ & MD & NAE & SC \\
\hline $\begin{array}{l}\text { Arithmetic } \\
\text { Filter }\end{array}$ & $\begin{array}{l}31.924 \\
7\end{array}$ & 33.0895 & 3.8760 & 113 & $\begin{array}{l}0.039 \\
1\end{array}$ & $\begin{array}{l}0.99 \\
78\end{array}$ \\
\hline $\begin{array}{l}\text { Geometric } \\
\text { Filter }\end{array}$ & $\begin{array}{l}252.15 \\
0\end{array}$ & 24.1142 & 98.925 & 252 & $\begin{array}{l}0.998 \\
8\end{array}$ & $\begin{array}{l}186 . \\
19\end{array}$ \\
\hline $\begin{array}{l}\text { Harmonic } \\
\text { Filter }\end{array}$ & $\begin{array}{l}252.15 \\
0\end{array}$ & 24.1142 & 98.925 & 252 & $\begin{array}{l}0.998 \\
8\end{array}$ & $\begin{array}{l}185 . \\
95\end{array}$ \\
\hline $\begin{array}{l}\text { Contra- } \\
\text { Harmonic } \\
\text { Filter }\end{array}$ & $\begin{array}{l}252.15 \\
0\end{array}$ & 24.1142 & 99.046 & 253 & $\mathrm{NaN}$ & $\mathrm{NaN}$ \\
\hline $\begin{array}{l}\text { Median } \\
\text { Filter }\end{array}$ & $\begin{array}{l}49.082 \\
3\end{array}$ & 31.2216 & 4.7516 & 135 & $\begin{array}{l}0.048 \\
0\end{array}$ & $\begin{array}{l}1.00 \\
64\end{array}$ \\
\hline $\begin{array}{l}\text { Max and } \\
\text { Min Filter }\end{array}$ & $\begin{array}{l}243.51 \\
9\end{array}$ & 24.2655 & 37.450 & 215 & $\begin{array}{l}0.378 \\
1\end{array}$ & $\begin{array}{l}1.05 \\
00\end{array}$ \\
\hline $\begin{array}{l}\text { Mid-Point } \\
\text { Filter }\end{array}$ & $\begin{array}{l}15.958 \\
0\end{array}$ & 36.1010 & 2.1084 & 89 & $\begin{array}{l}0.021 \\
3\end{array}$ & $\begin{array}{l}0.99 \\
75\end{array}$ \\
\hline
\end{tabular}

Table 4 shows the different measurement parameters after applying all the filters for Uniform noise.

TABLE IV. UNIFORM NOISE

\begin{tabular}{|c|c|c|c|c|c|c|}
\hline FILTER & MSE & PSNR & AD & MD & NAE & SC \\
\hline $\begin{array}{l}\text { Arithmeti } \\
\text { c Filter }\end{array}$ & 0.2494 & $\begin{array}{l}54.162 \\
3\end{array}$ & $\begin{array}{l}0.038 \\
7\end{array}$ & 66 & $\begin{array}{l}0.000390 \\
92\end{array}$ & 0.9998 \\
\hline $\begin{array}{l}\text { Geometri } \\
\text { c Filter }\end{array}$ & 0.0071 & $\begin{array}{l}69.646 \\
8\end{array}$ & $\begin{array}{l}0.000 \\
7476 \\
8\end{array}$ & 26 & $\begin{array}{l}0.000007 \\
5488\end{array}$ & 0.9997 \\
\hline $\begin{array}{l}\text { Harmonic } \\
\text { Filter }\end{array}$ & 0.0484 & $\begin{array}{l}61.282 \\
3\end{array}$ & $\begin{array}{l}0.005 \\
4\end{array}$ & 54 & $\begin{array}{l}0.000054 \\
459\end{array}$ & 0.9996 \\
\hline $\begin{array}{l}\text { Contra- } \\
\text { Harmonic } \\
\text { Filter }\end{array}$ & $\begin{array}{l}251.50 \\
9\end{array}$ & $\begin{array}{l}24.125 \\
3\end{array}$ & $\begin{array}{l}98.06 \\
3\end{array}$ & 252 & 0.9901 & 99.972 \\
\hline $\begin{array}{l}\text { Median } \\
\text { Filter }\end{array}$ & 0.0093 & $\begin{array}{l}68.445 \\
9\end{array}$ & $\begin{array}{l}0.001 \\
9\end{array}$ & 135 & $\begin{array}{l}0.000019 \\
065\end{array}$ & 0.9997 \\
\hline $\begin{array}{l}\text { Max and } \\
\text { Min Filter }\end{array}$ & 8.7633 & $\begin{array}{l}38.704 \\
1\end{array}$ & $\begin{array}{l}1.140 \\
6\end{array}$ & 160 & 0.0115 & 0.9988 \\
\hline $\begin{array}{l}\text { Mid- } \\
\text { Point } \\
\text { Filter }\end{array}$ & $\begin{array}{l}15.958 \\
0\end{array}$ & $\begin{array}{l}36.101 \\
0\end{array}$ & $\begin{array}{l}2.108 \\
4\end{array}$ & 89 & 0.0213 & 0.9975 \\
\hline
\end{tabular}

\section{CONCLUSION}

On seeing the factors revealed in the overhead tables we can conclude that which filter will be best for removing respective noise. This conclusion is stated below in the Table V.

TABLE V. FILTERS TO BE CHOSEN FOR DIFFERENT NOISES

\begin{tabular}{|l|l|}
\hline \multicolumn{1}{|c|}{ NOISES } & \multicolumn{1}{c|}{ FILTERS } \\
\hline Rayleigh Noise & Arithmetic Mean Filter \\
\hline Salt and Pepper Noise & Median Filter \\
\hline Gaussian Noise & Mid-Point Filter \\
\hline Uniform Noise & Geometric Mean Filter \\
\hline
\end{tabular}

\section{REFERENCES}

[1] R.C. Gonzalez and R.E.Woods“Digital Image Processing.

[2] Suresh Kumar, Papendra Kumar, Manoj Gupta, Ashok Kumar Nagawat, "Performance Comparison of Median and Wiener Filter in Image Denoising", International Journal of Computer Application, Vol.12 - No.4, November 2010

[3] C.Saravanan, R. Ponalagusamy"Gaussian Noise Estimation Technique for Gray Scale Images Using Mean Value". Journal of Theoretical and Applied Information technology. 2005-2007

[4] Pawan Patidar, Manoj Gupta and Sumit Srivastava, "Image De Noising by Various Filters for Different Noise", International Journal of Computer Application, November 2010.

[5] M.S.Alani, Digital Image Processing using Mat lab, University Bookshop, Sharqa, URA, 2008.

[6] G. Pok, J. Liu, and A. S. Nair, "Selective Removal of Impulse Noise Based on Homogeneity Level Information," IEEE Trans. Image Processing, vol. 12, pp.85-92, Jan. 2003.

[7] E. Abreu, M. Lightstone, S. Mitra, and K. Arakawa, "A new efficient approach for the removal of impulse noise from highly corrupted images," IEEE Trans. Image Processing, vol. 5, pp. 1012-1025, June 1996

[8] K. S. Srinivasan and D. Ebenezer, _A new fast and efficient decision based algorithm for removal of high density impulse noises, IEEE Signal Process. Lett. vol. 14, no. 3, pp. 189-192, Mar. 2007.

[9] S. P. Awate and R. T. Whitaker, "Higher-order image statistics for unsupervised, information-theoretic, adaptive, image filtering," in Proc IEEE Comput. Soc. Conf. Comput. Vis. Pattern Recognit., vol. 2. Jun. 2005, pp. 44-51.

[10] T. Batard and M. Berthier, "Spinor Fourier transform for image processing," IEEE J. Sel. Topics Signal Process., vol. 7, no. 4, pp. 605613, Aug. 2013.

[11] P. Blomgren and T. F. Chan, "Color TV: Total variation methods for restoration of vector-valued images," IEEE Trans. Image Process, vol. 7, no. 3, pp. 304-309, Mar. 1998.

[12] A. Buades, B. Coll, and J.-M. Morel, "A non-local algorithm for image denoising," in Proc. IEEE Comput. Soc. Conf. Comput. Vis. Pattern Recognit., vol. 2. Jun. 2005, pp. 60-65

[13] M. Lebrun, "An analysis and implementation of the BM3D image denoising method," Image Process. On Line, vol. 2, pp. 175-213, Aug. 2012

[14] M. Lebrun, M. Colom, and J. M. Morel, "The noise clinic: A universal blind denoising algorithm," in Proc. IEEE Int. Conf. Image Process, Oct. 2014, pp. 2674-2678.

[15] A. Levin and B. Nadler, "Natural image denoising: Optimality and inherent bounds," in Proc. IEEE Int. Conf. Comput. Vis. Pattern Recognit., vol. 2. Jun. 2011, pp. 2833-2840. 
[16] M. Lysaker, S. Osher, and X.-C. Tai, "Noise removal using smoothed normals and surface fitting," IEEE Trans. Image Process., vol. 13, no. 10, pp. 1345-1357, Oct. 2004.

[17] S. Osher, M. Burger, D. Goldfarb, J. Xu, and W. Yin, "An iterative regularization method for total variation-based image restoration," Multiscale Model. Simul., vol. 4, no. 2, pp. 460-489, 2005.

[18] T. Rahman, X.-C. Tai, and S. Osher, "A tv-stokes denoising algorithm," in Scale Space and Variational Methods in Computer Vision (Lecture Notes in Computer Science), vol. 4485. Berlin, Germany, Springer Verlag, 2007, pp. 473-483.

\section{AUTHORS' PROFILE}

Prashant Dwivedy received his B.Tech degree in Electronics \& Communication Engineering in 2014 from Gurukula Kangri Vishwavidyalaya, Haridwar, Uttarakhand and currently pursuing M.Tech in Digital Communication Engineering from NITTTR, Bhopal. His area of interest includes Digital Image Processing, Digital Signal Processing.

Dr. Anjali Potnis is Professor at Department of Electrical \& Electronics Engineering, National Institute of Technical Teachers ${ }^{\text {ee }}$ Training \& Research Bhopal. She has got a total of 16 years of teaching experience. She has published many research papers. Her area of interest includes Digital Image Processing and Digital Signal Processing.
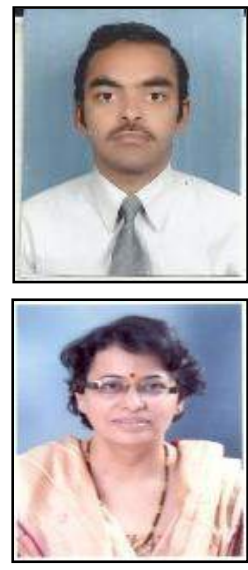

Madhuram Mishra received his B.E degree in Electronics \& Communication Engineering from Rajiv Gandhi Proudyogiki Vishwavidyalaya, Bhopal and currently pursuing M.Tech in Digital Communication Engineering from NITTTR, Bhopal. His area of interest includes Digital Image Processing and Digital Communication.

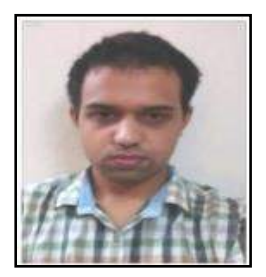

